\title{
A valorização das debêntures: fatores evidenciados na literatura
}

Diante do crescimento do mercado de debêntures verificado nos últimos anos e pela expectativa de conhecer quais são os aspectos que influenciam a valorização das debêntures, a presente pesquisa realizou um mapeamento de quais são os fatores discutidos na literatura nacional que influenciam na valorização deste título, para tanto realizou uma análise bibliográfica em artigos científicos publicados em eventos e periódicos, bem como teses de doutorado e mestrado. Isto permitiu identificar 18 estudos anteriores cujo os aspectos identificados como relevantes para a valorização das debêntures se dividem em dois grupos: os que permitem uma melhor avaliação da empresa como rating, setor, infraestrutura e principalmente o desempenho financeiro das empresas emissoras e grupo dos fatores que transmitem maior informação referente aos aspectos da emissão e que contribuem para que o debenturista possua mais garantias de receber os juros e o principal conforme o espectro da emissão, destacam-se: vencimento da emissão, volume da emissão, banco coordenador e as garantias.

Palavras-chave: Risco de Crédito; Valorização das Debêntures; Pesquisas anteriores.

\section{The valuation of debentures: factors evidenced in the literature}

In view of the growth of the debentures market verified in recent years and the expectation of knowing which aspects influence the valuation of debentures, the present research carried out a mapping of what are the factors discussed in the national literature that influence the valuation of this security, for both carried out a bibliographic analysis on scientific articles published in events and journals, as well as doctoral and master's theses. This made it possible to identify 18 previous studies whose aspects identified as relevant to the valuation of debentures are divided into two groups: those that allow a better assessment of the company as a rating, sector, infrastructure and mainly the financial performance of the issuing companies and a group of factors that transmit more information regarding the aspects of the issue and that contribute to the debenture holder having more guarantees of receiving the interest and the principal according to the spectrum of the issue, the following stand out: maturity of the issue, volume of the issue, coordinating bank and guarantees.

Keywords: Credit risk; Valuation of Debentures; Previous research.

Topic: Finanças Empresariais

Reviewed anonymously in the process of blind peer.
Received: 06/12/2019

Approved: 09/01/2020
Kliver Lamarthine Alves Confessor (iD

Universidade Federal de Pernambuco, Brasil

http://lattes.cnpq.br/6761541646953979

http://orcid.org/0000-0002-6972-634X

adm.kliver@gmail.com

Joséte Florencio dos Santos (1D

Universidade Federal de Pernambuco, Brasil

http://lattes.cnpq.br/5657418279526928

http://orcid.org/0000-0002-5366-2548

ifs@ufpe.br
Referencing this:

CONFESSOR, K. L. A.; SANTOS, J. F.. A valorização das debêntures: fatores evidenciados na literatura. Revista Brasileira de Administração Científica, v.11, n.1, p.16-23, 2020. DOI: http://doi.org/10.6008/CBPC2179-684X.2020.001.0002 


\section{INTRODUÇÃO}

As duas principais linhas de financiamento de longo prazo do mercado brasileiro podem ser obtidas por meio: do Banco Nacional de Desenvolvimento Econômico e Social (BNDES) e da emissão dos títulos de crédito emitido por empresas de capital aberto diretamente aos investidores - as debêntures. As empresas ao emitirem debêntures disponibilizam títulos que remuneram os credores, sob a forma de juros conforme os prazos e vencimento estabelecidos na emissão. Vale destacar que a emissão obteve destaque nos últimos anos, conforme ANBIMA (2014).

Diante desse crescimento, observa-se que os investidores demandam por informações que thes permitam discernir sobre qual investimento realizar a fim de evitar o risco de inadimplência e avaliar melhor a relação risco versus retorno, expressa pela taxa de juros da emissão e o valor da debênture. Assim, são vários os estudos anteriores direcionados a analisar os fatores que possuem influência no valor das debêntures, destaca-se (RODRIGUES et al., 2004; SHENG et al., 2008; AGUIAR, 2012; PAIVA, 2011; ESTEVES, 2014; PAULA, 2016). Estes autores buscaram compreender como a classificação do risco das empresas; prazo de resgate do capital investido; garantias oferecidas pelas debêntures; nível de governança corporativa; o valor da emissão e setor da empresa emissora se configuram como fatores determinantes do valor das debêntures.

Esta pesquisa realizou um mapeamento dos fatores discutidos na literatura nacional que influenciam na valorização das debêntures e consequentemente discutiu como se configura essa relação uma vez que são vários os tipos de informações influenciam os preços das debêntures e essas informações provocam alterações maiores ou menores em sua precificação, dependendo do contexto do mercado, da relevância da informação e do tempo que essas informações levam para serem incorporada pelo mercado, compondo, portanto, um conjunto de informações significativas para a compreensão da valorização das debêntures.

\section{REVISÃO TEÓRICA}

As debêntures são definidas pela no Lei 6.385/76, como valores mobiliários, registrados no Sistema Nacional de Debêntures e regulamentados pela Comissão de Valores Mobiliários, órgão responsável pela fiscalização do mercado de valores mobiliários. Esses títulos são considerados uma fonte de financiamento utilizada pelas empresas para captação de recursos pois geralmente possuem prazos, garantias e benefícios fiscais diferentes dos empréstimos bancários. São também de fácil adequação aos fluxos de pagamento e às condições de geração de caixa por parte das empresas (GIACOMINI, 2013).

Diante do exposto são apresentadas as características das debêntures, por exemplo, a natureza quanto á origem e emissão, classe, remuneração e garantias. Em referência a emissão de debêntures ocorrem duas classificações: públicas e privadas. As emissões privadas são voltadas a um grupo restrito de investidores e seu processo de emissão não exige o registro na CVM. Já as emissões públicas são direcionadas ao público em geral e somente podem ser realizadas por companhias abertas e com registro na Comissão de Valores Mobiliários. 
As emissões públicas são vinculadas a um Programa de Distribuição de Valores Mobiliários e estão amparadas pela Instrução CVM no 400, no qual determina que a companhia esteja sempre assessorada por instituições intermediárias, as quais serão responsáveis pelas informações, verificações, distribuição e estruturação da debênture. Outro requisito para as emissões públicas é a contratação de agente fiduciário, este representa os interesses dos debenturistas junto à companhia emissora e são responsáveis por verificar o cumprimento das condições pactuadas na escritura e pela elaboração de relatórios de acompanhamento.

Quanto à forma, podem ser classificadas em nominativas ou escriturais. Para as primeiras, a companhia emite a debênture em nome do investidor inicial e o registro e o controle das transferências são realizados pela companhia emissora em livro próprio de registro de debêntures nominativas. Nesse caso, é opcional a contratação de serviços de escrituração e guarda dos livros de registros da emissão e das transferências do ativo. Quanto à classe, são três categorias: as debêntures simples, que não conferem direito de conversão em ações; as debêntures conversíveis, que permitem a conversão em ações da companhia emissora; e as debêntures permutáveis, que permitem a troca do título por ações de outras companhias descritas na escritura da emissão, contendo, portanto, uma opção de compra embutida de ações de outras companhias.

Na remuneração da debênture observa-se um prêmio exigido pelo investidor composto de duas faixas de remuneração: a primeira delas reflete a taxa de juros básica da economia e a segunda reflete a taxa de juros adicional que as instituições emissoras de dividas se propõem a pagar ao investidor pelos riscos adicionais em comparação com os ativos livres de risco. Isto posto, a valorização da debênture compreende o resultado adicional à taxa livre de risco. Sheng (2005) aponta que o principal risco que compõe essa valorização é o risco de inadimplência.

Portanto as debêntures podem ser classificadas quanto a remuneração sob duas alternativas: juros fixos ou variáveis. No Brasil a forma mais comum é baseada em taxas prefixadas, sejam elas: taxas de juros pós-fixada; Taxa Referencial; Taxa de Juros de Longo Prazo; Taxa Básica Financeira; Atualização monetária (índice de preços) e variação cambial. Convém destacar que em uma mesma emissão de debêntures pode ocorrer mais de uma forma de remuneração, que é a denominada remuneração mista.

No tocante ao vencimento as emissões de debêntures se dividem entre aquelas que possui um prazo determinado e as que são perpetuas, neste último caso, o vencimento fica condicionado às situações de inadimplemento de pagamento de juros, dissolução da companhia e outros eventos conforme forem mencionados no prospecto da emissão.

De acordo com o estabelecido na Lei № 6.404, a emissão das debêntures poderá ser efetuada com ou sem garantias. Essas garantias têm como objetivo assegurar aos debenturistas o cumprimento da obrigação do principal, podendo ser cumulativas e substituídas desde que registrado na escritura de emissão. Os principais tipos de garantias são apresentados no Quadro 1 a seguir. Após a conceituação sobre debêntures, seus fundamentos e diversas classificações, sobretudo no que diz respeito a forma com as debêntures são remuneradas, a seção a seguir apresentará o delineamento metodológico da presente pesquisa bem como os procedimentos de coleta de dados. 
Quadro 1: Classificação das debêntures conforme os tipos de garantias.

\begin{tabular}{|l|l|}
\hline \multicolumn{1}{|c|}{$\begin{array}{c}\text { Tipo de } \\
\text { garantia }\end{array}$} & \multicolumn{1}{c|}{ Característica } \\
\hline Garantia Real & $\begin{array}{l}\text { Envolve o comprometimento de bens ou direitos que não poderão ser negociados sem a aprovação dos } \\
\text { debenturistas, para que a garantia não fique comprometida. São exemplos de garantias reais: móveis e } \\
\text { imóveis dados em hipoteca, alienação e cessão fiduciária, penhor ou anticrese pela companhia emissora, por } \\
\text { seu conglomerado, ou mesmo por terceiros }\end{array}$ \\
\hline $\begin{array}{l}\text { Garantia } \\
\text { Flutuante }\end{array}$ & Assegura privilégio sobre o ativo da emissora, mas não impede a negociação dos bens que compõe esse ativo \\
\hline Quirografárias & $\begin{array}{l}\text { O debenturista não tem nenhuma garantia ou preferência no caso de liquidação da companhia, concorrendo } \\
\text { em igualdade de condições com os demais credores quirografários da emissora }\end{array}$ \\
\hline Subordinadas & $\begin{array}{l}\text { São aquelas que estão especificamente subordinadas a outros tipos de dívida. Embora os detentores de } \\
\text { dívida subordinada estejam abaixo de todos os outros credores de longo prazo quanto à liquidação e o } \\
\text { pagamento de juros, suas reivindicações precisam ser satisfeitas antes que as dos acionistas ordinários e } \\
\text { preferenciais }\end{array}$ \\
\hline
\end{tabular}

\section{METODOLOGIA}

O objetivo desta pesquisa foi realizar um mapeamento dos estudos direcionados a identificar os fatores que influenciam a valorização das debêntures em pesquisas nacionais. Sendo assim a pesquisa é caracterizada como descritiva, pois procura identificar quais os fatores discutidos na literatura que possuem relação com aa valorização das debêntures. Com relação aos procedimentos, caracteriza-se como bibliográfica já que explica um problema a partir da análise de artigos publicados em eventos e revistas acadêmicas e teses e dissertações. $O$ universo desse estudo compreendeu os periódicos científicos nacionais independente do qualis da revista, bem como os principais eventos de administração e contabilidade que pudessem ter em seus anais artigos sobre esta temática.

Para seleção da amostra, realizou-se os seguintes procedimentos: Extrair do site da Qualis CAPES todos os periódicos nas áreas de Administração, Contabilidade e Turismo; identificar nos periódicos e eventos artigos que contemplam a temática por meio das palavras-chaves: debêntures, bonds, precificação de debêntures; avaliação das debêntures; spread das debêntures; valorização das debêntures.

Desta feita foram separados os artigos cujo objetivo estava voltado para analisar os fatores que tivessem relação com a avaliação das debêntures, permitindo mapear os fatores evidenciados na literatura que possuem relação positiva com o valor das debêntures. A seção a seguir apresenta os principais artigos encontrados na literatura e que atendem aos requisitos metodológicos da presente pesquisa.

\section{RESULTADOS E DISCUSSÃO}

No Brasil, diversas pesquisas foram realizadas em busca de melhor compreender a formação do spread dos títulos corporativos, em sua maioria, testes foram realizados para verificar a influência do rating. A seguir, a Tabela 1 apresenta o mapeamento das pesquisas que fundamentam a análise de dados deste estudo.

Como se pode observar foram identificados 18 trabalhos entre artigos científicos publicados em eventos e periódicos, bem como teses de doutorado e mestrado. A seguir, estes trabalhos serão comentados com vistas a alcançar a discussão proposta no objetivo desta pesquisa: mapear os fatores relacionados na literatura como relevantes para a valorização das debêntures. 
Tabela 1: Mapeamento das pesquisas voltadas para a avaliação das debêntures.

\begin{tabular}{|c|c|c|c|}
\hline Título & $\begin{array}{c}\text { Natureza da } \\
\text { pesquisa }\end{array}$ & $\begin{array}{c}\text { Ano de } \\
\text { Publicação }\end{array}$ & Instituição \\
\hline $\begin{array}{l}\text { Determinação das taxas de juros das debêntures no mercado } \\
\text { brasileiro. }\end{array}$ & Artigo de Evento & 2002 & Encontro Brasileiro de Finanças \\
\hline $\begin{array}{l}\text { Ensaios sobre emissões de corporate bonds (debêntures) no } \\
\text { mercado brasileiro }\end{array}$ & Tese & 2005 & Fundação Getúlio Vargas \\
\hline $\begin{array}{l}\text { Preço de Emissão Primária de Debêntures no Brasil: } 2000 \text { - } \\
2004\end{array}$ & Artigo de Evento & 2006 & Encontro Brasileiro de Finanças \\
\hline $\begin{array}{l}\text { A influência do risco de liquidez no apreçamento de } \\
\text { debêntures }\end{array}$ & Mestrado & 2006 & Fundação Getúlio Vargas \\
\hline A importância do rating na padronização de debêntures. & $\begin{array}{l}\text { Artigo de } \\
\text { Periódico }\end{array}$ & 2006 & $\begin{array}{l}\text { RAE - Revista de Administração de } \\
\text { Empresas }\end{array}$ \\
\hline $\begin{array}{l}\text { A precificação do spread de liquidez no mercado secundário } \\
\text { de debêntures }\end{array}$ & Mestrado & 2007 & Fundação Getúlio Vargas \\
\hline Aplicação de redes neurais na precificação de debêntures & Mestrado & 2008 & Fundação Getúlio Vargas \\
\hline $\begin{array}{l}\text { Avaliação das diferenças de ratings em emissões de } \\
\text { debêntures no Brasil: } 2000 \text { a } 2007\end{array}$ & Artigo de Evento & 2008 & SEMEAD \\
\hline Liquidez das debêntures no mercado brasileiro & $\begin{array}{l}\text { Artigo de } \\
\text { Periódico }\end{array}$ & 2008 & $\begin{array}{l}\text { RAUSP - Revista de Administração da } \\
\text { Universidade de São Paulo }\end{array}$ \\
\hline Fatores que influenciam o spread das debêntures no Brasil & Mestrado & 2009 & Fundação Getúlio Vargas \\
\hline Pricing corporate bonds in Brazil & $\begin{array}{l}\text { Artigo de } \\
\text { Periódico }\end{array}$ & 2009 & Journal of Business Research \\
\hline $\begin{array}{l}\text { Composição das dívidas corporativas no Brasil: Fatores que } \\
\text { explicam a emissão de debêntures }\end{array}$ & Mestrado & 2010 & Fundação Getúlio Vargas \\
\hline Formação de preço de debêntures no Brasil & Tese & 2011 & $\begin{array}{l}\text { Faculdade de Economia, Administração } \\
\text { e Contabilidade }\end{array}$ \\
\hline $\begin{array}{l}\text { Estudo da precificação no lançamento de títulos de dívida de } \\
\text { empresas brasileiras no exterior }\end{array}$ & Mestrado & 2012 & $\begin{array}{l}\text { Faculdade de Economia, Administração } \\
\text { e Contabilidade }\end{array}$ \\
\hline $\begin{array}{l}\text { Os efeitos dos mecanismos de governança corporativa sobre } \\
\text { os ratings de crédito das debêntures }\end{array}$ & $\begin{array}{l}\text { Artigo de } \\
\text { Periódico }\end{array}$ & 2012 & Revista de Negócios \\
\hline $\begin{array}{l}\text { O impacto da liquidez nos retornos esperados das } \\
\text { debêntures brasileiras }\end{array}$ & $\begin{array}{l}\text { Artigo de } \\
\text { Periódico }\end{array}$ & 2013 & $\begin{array}{l}\text { RAE - Revista de Administração de } \\
\text { Empresas }\end{array}$ \\
\hline $\begin{array}{l}\text { The role of bond covenants and short-term debt: evidence } \\
\text { from Brazil }\end{array}$ & $\begin{array}{l}\text { Artigo de } \\
\text { Periódico }\end{array}$ & 2013 & BAR - Brazilian Administration Review \\
\hline $\begin{array}{l}\text { Um estudo de caso com base em emissões de empresas } \\
\text { listadas e não listadas em bolsa de valores no Brasil. }\end{array}$ & Mestrado & 2014 & $\begin{array}{l}\text { Fundação Escola de Comércio Álvares } \\
\text { Penteado - FECAP }\end{array}$ \\
\hline
\end{tabular}

Sheng (2005) e Sheng et al. (2006) em busca de identificar aspectos que afetam o valor das debêntures, identificaram que análises de rating, liquidez e desenhos de contratos nas emissões de diferentes ratings possuem relação com à formação do spread das debêntures. Secches (2006) contribuiu para a avaliação do valor das debêntures ao incluir o risco de liquidez entre os fatores que influenciam o apreçamento dos títulos de renda fixa corporativos brasileiros. Por sua vez, Sheng et al. (2008) replicaram sua pesquisa de 2006 e com o reajuste do modelo empregado para as análises concluíram que o volume de emissão de papéis é uma variável relevante na determinação da taxa de juros das debêntures.

Paiva et al. (2006) analisaram o preço das emissões primárias de debêntures de uma amostra de títulos indexados ao DI e ao IGP-M, e indicaram uma relação negativa entre preço e maturidade, e a importância da probabilidade de default na determinação dos spreads. Em seguida, destaca-se Paiva, Savoia et al. (2008) e Paiva et al. (2009), constataram que variáveis relacionadas ao risco de crédito são relevantes na determinação do spread e que emissões em percentual do DI tendem a ter menor spread que aquelas remuneradas por inflação mais taxa.

Curi (2008), por sua vez, inovou ao aplicar redes neurais para a precificação de debêntures. Esta pesquisa comparou resultados obtidos com trabalhos que utilizaram regressões lineares e concluiu que a técnica de redes neurais apresenta resultados superiores aos métodos estimados por pooling. Costa (2009) verificou quais fatores influenciam o spread e o rating das emissões de debêntures no Brasil e encontrou uma relação positiva, em média, entre risco-país e spread. Cruz (2010) abordou as causas de emissões de dívidas 
corporativas públicas e sugeriu que o destino dos recursos captados e o setor de atuação da empresa são variáveis importantes para a composição de dívidas corporativas

Em seu estudo Silva et al. (2012) tiveram como objetivo investigar se a qualidade das práticas de governança corporativa das empresas listadas na Bovespa tem alguma relação com a qualidade dos ratings e spread das debêntures emitidas por estas empresas, no período de 2005 a 2007. Para verificar a influência das práticas de governança corporativa sobre os spreads das debêntures, foi utilizado o método dos mínimos quadrados ordinários, seus resultados sugerem a influência do desempenho contábil sobre os spreads das debêntures e que as empresas que têm maiores desempenhos não se preocupam em serem mais atrativas ofertando maiores spreads aos seus papéis.

Paiva (2011) verificou que rating é relevante pois percebeu a sua influência sobre formação dos preços de emissões de debêntures. Nesse sentido, Pereira (2012) também encontrou relevância da variável rating e desempenho econômico para a formação dos spreads das emissões de debêntures no mercado brasileiro.

Giacomini et al. (2013) estudaram o impacto do risco de liquidez nos retornos excedentes esperados das debêntures no mercado secundário. Sete proxies foram utilizadas para testar o impacto do risco de liquidez nos spreads das debêntures e a hipótese nula de que não há prêmio de liquidez para o mercado secundário de debêntures no Brasil foi rejeitada para três das sete proxies (spread de compra e venda, valor nominal de emissão e quantidade emitida) e os prêmios encontrados são muito baixos, o que vai ao encontro do trabalho de Gonçalves (2007), apontando que o risco de liquidez não é um fator importante na composição das expectativas dos investidores no mercado secundário de debêntures. Silva et al. (2013) discutiram a relação entre covenants e alavancagem financeira através de títulos de dívida de curto e longo prazo, encontraram evidências de que há uma relação negativa entre crescimento e dívida de curto prazo.

Por sua vez Esteves (2014), ao estudar quais os principais fatores determinantes na formação do spread em emissões debêntures encontrou um prêmio adicional às empresas não listadas; a influência na formação do spread de acordo com a escolha do banco coordenador líder do processo; a relação estatisticamente significante entre os indicadores contábeis e a formação do spread, porém, em seu modelo algumas variáveis estatisticamente significantes para a formação do spread, como apresentado em outros trabalhos, como variáveis ambientais, garantia, nível de regulação do setor, índices de governança corporativa, maturidade da dívida, volume de emissão, cláusulas restritivas contratuais, rating, não foram incluídas. Diante do rastreamento das pesquisas analisadas foi possível desenvolver o Quadro 02 que resume principais trabalhos acadêmicos sobre avaliação das debêntures, identificando os resultados alcançados.

Quadro 2: Principais trabalhos acadêmicos sobre precificação de debêntures.

\begin{tabular}{|l|l|}
\hline \multicolumn{1}{|c|}{ Trabalho } & \multicolumn{1}{c|}{ Resultados } \\
\hline Mellone et al. (2002) & O rating mostrou evidência de que esta variável contribui para a formação do preço. \\
\hline Sheng (2005) & Rating, liquidez e desenhos de contratos possuem relação com à formação do spread. \\
\hline Sheng et al. (2006) & $\begin{array}{l}\text { A expectativa do mercado internacional em relação ao mercado brasileiro, o tipo de setor e volume de } \\
\text { emissão e o rating são importantes para se definir o spread }\end{array}$ \\
\hline Secches (2006) & $\begin{array}{l}\text { Concluiu que o risco de liquidez é um dos fatores que influenciam o apreçamento dos títulos de renda } \\
\text { fixa corporativos brasileiros. }\end{array}$ \\
\hline Gonçalves & A hipótese nula de que não existe prêmio de liquidez embutido nos spreads foi rejeitada por todas as \\
\hline
\end{tabular}




\begin{tabular}{|c|c|}
\hline (2007) & proxies analisadas \\
\hline Sheng et al. (2008) & $\begin{array}{l}\text { O volume de emissão de papéis é uma variável relevante na determinação da taxa de juros quando da } \\
\text { emissão das debêntures. }\end{array}$ \\
\hline Paiva et al. (2006) & $\begin{array}{l}\text { Seus resultados sugerem que existe uma relação negativa entre preço e maturidade, e a importância da } \\
\text { probabilidade de default na determinação dos spreads foi confirmada. }\end{array}$ \\
\hline Paiva et al. (2008) & $\begin{array}{l}\text { Constataram que variáveis relacionadas ao risco de crédito são relevantes na determinação do spread e } \\
\text { que emissões em percentual do DI tendem a ter menor spread que aquelas remuneradas por inflação } \\
\text { mais taxa. }\end{array}$ \\
\hline Costa (2009) & $\begin{array}{l}\text { Encontrou-se relação positiva em média entre risco-país e spread e as análises indicam que em média } \\
\text { quanto maior é o rating, menor o spread pago. }\end{array}$ \\
\hline Cruz (2010) & $\begin{array}{l}\text { O destino dos recursos captados e o setor de atuação da empresa são variáveis importantes para a } \\
\text { composição de dívidas corporativas. }\end{array}$ \\
\hline Silva et al. (2010) & $\begin{array}{l}\text { Os resultados sugerem a influência do desempenho contábil sobre os spreads das debêntures e que as } \\
\text { empresas que têm maiores desempenhos não se preocupam em serem mais atrativas ofertando } \\
\text { maiores spreads aos seus papéis. }\end{array}$ \\
\hline Paiva (2011) & Encontrou a influência do rating sobre formação dos preços de emissões de debêntures. \\
\hline Pereira (2012) & $\begin{array}{l}\text { Encontrou relevância da variável rating e desempenho econômico para a formação dos spreads das } \\
\text { emissões de debêntures no mercado brasileiro. }\end{array}$ \\
\hline $\begin{array}{l}\text { Giacomini et al. } \\
(2013)\end{array}$ & $\begin{array}{l}\text { Apontam para a suspeita de que o risco de liquidez não é um fator importante para as expectativas dos } \\
\text { investidores no mercado secundário. }\end{array}$ \\
\hline Silva et al. (2013) & $\begin{array}{l}\text { Covenants e dívida de curto prazo podem ser considerados substitutos na atenuação de conflitos de } \\
\text { agência. Há uma relação negativa entre dívidas de curto prazo e oportunidades de crescimento, que } \\
\text { pode ser reduzida se utilizando covenants. }\end{array}$ \\
\hline Esteves (2014) & $\begin{array}{l}\text { Encontrou um prêmio adicional às empresas não listadas; a influência na formação do spread de acordo } \\
\text { com a escolha do banco coordenador líder do processo; a relação estatisticamente significante entre os } \\
\text { indicadores contábeis e a formação do spread. }\end{array}$ \\
\hline
\end{tabular}

Após o mapeamento dos estudos anteriores que visavam compreender os fatores que influenciam a valorização das debêntures, destaca-se que dentre os fatores mais significativos estão as variáveis que permitem uma melhor avaliação da empresa emissora, e, portanto, são capazes de mitigar o risco de crédito, como por exemplo: rating, setor, infraestrutura e principalmente o desempenho financeiro das empresas emissoras. Enquanto as variáveis que transmitem maior informação referente aos aspectos da emissão e que contribuem para que o debenturista possua mais garantias de receber os juros e o principal conforme o espectro da emissão, destacam-se: vencimento da emissão, volume da emissão, banco coordenador e as garantias.

\section{CONCLUSÕES}

Tendo em vista a importância das debêntures no que concerne as discussões referente ao financiamento empresarial, fonte alternativa para captação de recurso e mecanismo de investimento no mercado financeiro, a presente pesquisa teve como objetivo realizar um levantamento bibliográfico dos principais fatores discutidos na literatura nacional que possuem relação com a valorização das debêntures.

Neste mapeamento foram encontradas 18 pesquisas que estudaram aspectos que afetam a valorização das debêntures, sendo 2 teses, dos anos de 2005 e 2011; 7 trabalhos de mestrado, defendidas em sua maioria na FGV/SP. E nove artigos publicados, sendo 6 em periódicos e 3 em eventos. $O$ que denota que boas oportunidades de pesquisa na área de precificação e avaliação de debêntures. Também se observou que o método de análise predominante entre os artigos foi a regressão linear múltipla uma vez que consiste em uma técnica de análise multivariada cuja finalidade é identificar os efeitos independentes de um conjunto de variáveis sobre a variável dependente, portanto, configura-se como a técnica mais coerente.

Esta pesquisa amplia as discussões voltadas para o conflito de agência presente entre credores e 
empresas, dado que em uma relação de empréstimos, os credores passam a encontrar a possibilidade de não reaver seus recursos, por conta da incapacidade ou não interesse de pagamento por parte dos tomadores de recursos, afetando significativamente o risco de inadimplência. Como sugestões para pesquisas futuras se estima discutir como as cláusulas restritivas - covenants podem exercer influência sobre as debêntures por meio de análises teóricas e empíricas e ampliar o escopo deste estudo para as pesquisas internacionais.

\section{REFERÊNCIAS}

COSTA, D. A. D.. Fatores que influenciam o spread das debêntures no Brasil. Dissertação (Mestrado em Finanças e Economia Empresarial) - Fundação Getúlio Vargas, São Paulo, 2009.

CRUZ, F. B.. Composição das dívidas corporativas no Brasil: Fatores que explicam a emissão de debêntures. Dissertação (Mestrado em Finanças e Economia Empresarial) - Fundação Getúlio Vargas, São Paulo, 2010.

CURI, L. Z.. Aplicação de redes neurais na precificação de debêntures. Dissertação (Mestrado em Finanças e Economia Empresarial) - Fundação Getúlio Vargas, São Paulo, 2008.

ESTEVES, M. L.. Fatores determinantes para a formação do spread de debêntures de empresas não financeiras: Um estudo de caso com base em emissões de empresas listadas e não listadas em bolsa de valores no Brasil. Dissertação (Mestrado) - Fundação Escola de Comércio Álvares Penteado, São Paulo, 2014.

GIACOMINI, B. H.; SHENG, H. H.. O impacto da liquidez nos retornos esperados das debêntures brasileiras. Revista de Administração de Empresas, São Paulo, v.48, n.1, p.80-97, 2013.

GONÇALVES, P. E.. A precificação do spread de liquidez no mercado secundário de debêntures. Dissertação (Mestrado em Finanças e Economia Empresarial) - Fundação Getúlio Vargas, São Paulo. 2007.

MELLONE, G.; EID JÚNIOR, W.; ROCHMAN, R.. Determinação das taxas de juros das debêntures no mercado brasileiro. In: ENCONTRO DE FINANÇAS, 2. Anais. Rio de Janeiro, 2002.

PAIVA, E. V. S.; SAVOIA, J. R. F.. Preço de Emissão Primária de Debêntures no Brasil: 2000 - 2004. In: ENCONTRO BRASILEIRO DE FINANÇAS, 6. Anais. 2006. p.1-15.
PAIVA, E. V. S.; SAVOIA, J. R. F.. Pricing corporate bonds in Brazil. Journal of Business Research, n.62, p.916-919, 2009.

PAIVA, E. V. S.; SAVOIA, J. R. F.; CORRAR, L. J.. Avaliação das diferenças de ratings em emissões de debêntures no Brasil: 2000 a 2007. In: SEMEAD, 11. Anais. São Paulo, 2008. p.1-15.

PAIVA, E. V. S.. Formação de preço de debêntures no Brasil. Tese (Doutorado em 2011) - Universidade de São Paulo, São Paulo, 2011.

PEREIRA, B. L.. Estudo da precificação no lançamento de títulos de dívida de empresas brasileiras no exterior. Dissertação (Mestrado em Ciências) - Universidade de São Paulo, 2012.

SECCHES, P.. A influência do risco de liquidez no apreçamento de debêntures. Dissertação (Mestrado) Fundação Getúlio Vargas, São Paulo, 2006.

SHENG, H. H.. Ensaios sobre emissões de corporate bonds (debêntures) no mercado brasileiro. Tese (Doutorado em Administração de Empresas) - Fundação Getúlio Vargas, São Paulo, 2005.

SHENG, H. H.; SAITO, R.. A importância do rating na padronização de debêntures. Revista de Administração de Empresas, São Paulo, v.46, n.2, p.44-54, 2006.

SHENG, H. H.; SAITO, R.. A Liquidez das debêntures no mercado brasileiro. Revista de Administração da Universidade de São Paulo, São Paulo, v.43, n.2, p.176-185, 2008.

SILVA, E. S.; SANTOS, J. F.; ALMEIDA, M. A.. Os efeitos dos mecanismos de governança corporativa sobre os ratings de crédito das debêntures. Revista de Negócios, v.17, n.3, p.8093, 2012.

A CBPC - Companhia Brasileira de Produção Científica (CNPJ: 11.221.422/0001-03) detém os direitos materiais desta publicação. Os direitos referem-se à publicação do trabalho em qualquer parte do mundo, incluindo os direitos às renovações, expansões e disseminações da contribuição, bem como outros direitos subsidiários. Todos os trabalhos publicados eletronicamente poderão posteriormente ser publicados em coletâneas impressas sob coordenação da Sustenere Publishing, da Companhia Brasileira de Produção Científica e seus parceiros autorizados. Os (as) autores (as) preservam os direitos autorais, mas não têm permissão para a publicação da contribuição em outro meio, impresso ou digital, em português ou em tradução. 